\title{
RESPOSTA DIFERENCIAL DE ACESSOS DE SEMENTES DE PHYSALIS PERUVIANA AO NaCl
}

\author{
Warley de Souza Matos ${ }^{1}$; Marilza Neves do Nascimento ${ }^{2}$; Natália dos Santos Barroso ${ }^{3}$; \\ Josandra Souza Teles Fonseca ${ }^{4}$ \\ 1. Bolsista PROBIC/UEFS, Graduando em Agronomia, Universidade Estadual de Feira de Santana, e-mail: \\ warleysouza78@hotmail.com.br \\ 2. Orientador, Departamento de Biologia, Universidade Estadual de Feira de Santana, e-mail: marilzaagro@hotmail.com \\ 3. Participante do projeto, Universidade Estadual de Feira de Santana, e-mail: nataliasbarroso@yahoo.com.br \\ 4. Participante do projeto, Universidade Estadual de Feira de Santana, e-mail: josandrateles@hotmail.com.br
}

PALAVRAS-CHAVE: Estresse salino, germinação, fisális.

\section{INTRODUÇÃO}

A germinação de sementes e o estabelecimento de plântulas são os estádios de desenvolvimento mais sensíveis ao estresse salino. O uso de soluções salinas tem ajudado a compreender o processo germinativo e crescimento inicial das plântulas, especialmente por permitir que algumas espécies desenvolvam mecanismos fisiológicos de tolerância sem comprometer o desenvolvimento naquelas condições (Esteves e Suzuki, 2008).

Outro fator que pode contribuir para o pouco sucesso da germinação de sementes em ambientes estressantes é a viabilidade das sementes. Após a dispersão, a viabilidade tende a diminuir naturalmente, sendo um processo controlado pelas condições fisiológicas das sementes e do ambiente de armazenamento (Carvalho e Nakagawa, 2012). A depender da espécie e variedade, as sementes podem manter o embrião viável por longos períodos de tempo, contudo a sensibilidade a condições de ambiente de estresse podem sofrer alterações. Em geral, sementes mais velhas mostram uma cinética de germinação diferente quando comparada as sementes recém-colhidas (Marcos Filhos, 2005).

Devido à maior parte de solos salinos serem encontrados na região do semiárido nordestino, torna-se importante estudar e conhecer os mecanismos de tolerância desenvolvido pelas plantas e sementes, ainda em estágios iniciais de desenvolvimento, e identificar progênies com tolerância esse tipo de adversidade ambiental.

Nesse contexto, pretende-se ampliar os estudos com sementes de Physalis peruviana também conhecida no Brasil como fisális, pertencente à família Solanaceae. Essa espécie é considerada medicinal com diversas propriedades terapêuticas além do potencial nutraceutico dos frutos, e vem se mostrando moderadamente tolerante ao estresse salino, apesar apresentar uma certa sensibilidade durante a emergência das plântulas (Yildirim et al., 2011).

Assim, este estudo tem como objetivo avaliar o efeito da salinidade na germinação de diferentes acessos de sementes de Physalis peruviana em condições de incubação controlada.

\section{METODOLOGIA}

Os frutos maduros de Physalis peruviana foram coletados manualmente nos anos de 2011, 2012, 2014 e 2015, no Horto Florestal da Universidade Estadual de Feira de Santana. As sementes foram retiradas sob água corrente até a separação completa da polpa, secas sobre papel filtro em temperatura ambiente (condições de laboratório) e foram mantidas em geladeira até a realização dos ensaios no Laboratório de Germinação (LAGER/HORTO/UEFS).

Para os experimentos de germinação dos diferentes acessos descritos, sementes de $P$. peruviana foram dispostas em placas de Petri, contendo duas folhas de papel germitest (semi- 
esterilizados em estufa de secagem a $105^{\circ} \mathrm{C}$, por 4 horas), umedecidas com $3 \mathrm{ml}$ de água deionizada (controle) e dois níveis de salinidade (um na fase assintomática do estresse salino que será considerada aquele que proporcione $50 \%$ da germinação máxima e outro no qual não ocorre germinação). As placas contendo as sementes foram mantidas seladas com filme PVC e acondicionadas em câmara de germinação (Eletrolab) ajustada na temperatura de $20-30{ }^{\circ} \mathrm{C}$, e fotoperíodo de 12 horas, durante 28 dias. $\mathrm{O}$ número de sementes germinadas foram obtidos diariamente sendo consideradas germinadas as sementes que emitiram a radícula $(1-2 \mathrm{~mm})$. Os resultados obtidos foram expressos em porcentagem (\%) de germinação final, além de obter e comparar o tempo médio, velocidade média de germinação ( dias $^{-1}$ ) e o índice de velocidade de germinação em cada tratamento. Cada tratamento foi composto por quatro repetições constituído por 50 sementes. Equações de regressão foram utilizadas para representar os resultados de \% de germinação das sementes. Outras variáveis foram submetidas a análise de variância e as médias comparadas por teste de Tukey em nível de 5\% de probabilidade e teste $\mathrm{T}$ de student, utilizando o programa computacional SISVAR (Ferreira, 2011).

\section{RESULTADOS E DISCUSSÃO}

De acordo com os gráficos mostrados na Figura 1 pode-se perceber que houve forte tendência na diminuição na porcentagem de germinação a medida que concentração salina aumentou. Para o tratamento onde a concentração salina foi de $0 \mathrm{dS} \cdot \mathrm{m}^{-1}$ os índices de germinação foram superiores a 90\%, independente do acesso avaliado. Porém, quando submetidas a concentração salina de $10 \mathrm{dS} \cdot \mathrm{m}^{-1}$ as percentagens de germinação variaram entre $55 \%$ e $90 \%$. Já para concentração de $16 \mathrm{dS} \cdot \mathrm{m}^{-1}$ os índices de germinação reduziram-se para valores abaixo de $24 \%$. Esse comportamento também foi verificado nos estudos realizados por Yildirim et al. (2011) e Souza et al. (2014), evidenciado que a espécie apresenta tolerância a salinidade, sendo esta capaz de germinar em ambientes com elevada concentração de sais.
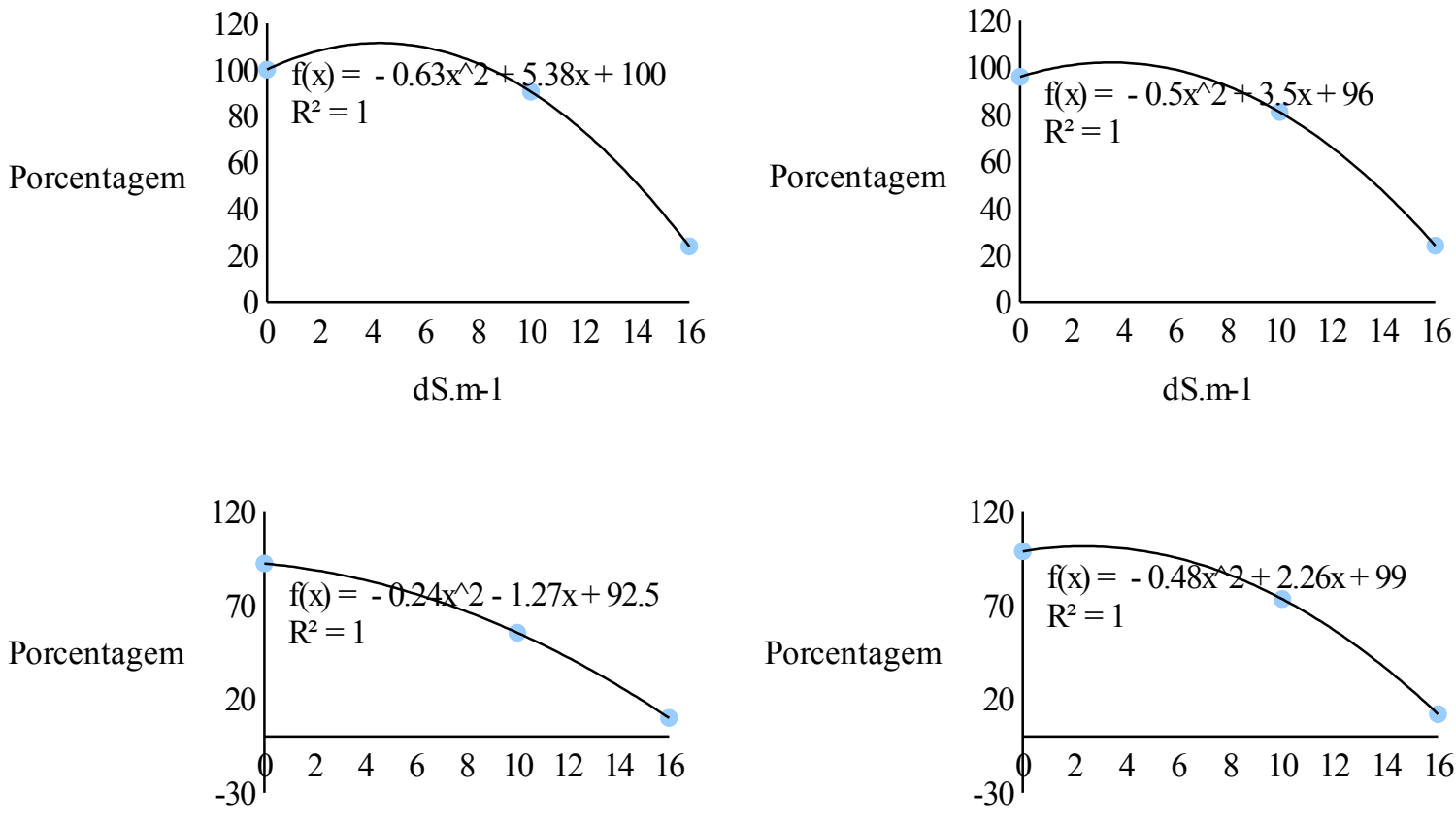

dS.m-1

dS.m-1 
Figura 1. Germinação de sementes de Physalis peruviana coletadas e armazenadas em 2011 (A), 2012 (B), 2014 (C) e 2015 (D) submetidas a três concentrações de solução salina (dS.m $\left.{ }^{1}\right)$.

A Tabela 1 mostra o percentual de sementes germinadas reidratadas após estarem submetidas a 28 dias de estresse salino, sob as concentrações de $0 \mathrm{ds} . \mathrm{m}^{-1}, 10 \mathrm{dS} . \mathrm{m}^{-1}$ e $16 \mathrm{dS} . \mathrm{m}^{-}$ 1 de $\mathrm{NaCl}$. Após serem reidratadas, foi possível verificar que as sementes tiveram altos índices de germinação. As sementes dos acessos de 2011, 2012 e 2015 que estavam submetidas a maior concentração salina $\left(16 \mathrm{ds} \cdot \mathrm{m}^{-1}\right)$, quando reidratadas, atingiu porcentagem de germinação igual ou superior a $80 \%, 7$ dias após a reidratação, mostrando que a presença do sal no meio, nesta concentração, tem um efeito osmótico e não tóxico as estas sementes. Porém as sementes produzidas e armazenadas em 2014 apresentou baixa porcentagem de germinação mesmo após a reidratação. Estes resultados podem indicar baixa qualidade fisiológica do acesso de sementes coletadas em 2014, pois quando comparado aos resultados obtidos para os demais acessos avaliados, apenas este não foi capaz de germinar após o estresse. Demonstrando que o estresse salino pode ser uma ferramenta para a diferenciação da qualidade fisiológica de acessos de sementes.

Tabela 1. Porcentagem de germinação de sementes de Physalis peruviana com diferentes tempos de armazenamento reidratadas pós estresse salino.

\begin{tabular}{cccccccccc}
\hline \multicolumn{10}{c}{$\%$ Germinação - Pós estresse salino } \\
\hline \multicolumn{10}{c}{$0 \mathrm{dm}^{-1}$} \\
\hline \multirow{2}{*}{ ACESSO } & $\begin{array}{c}\mathrm{N}^{\mathrm{o}} \\
\text { sementes }\end{array}$ & $\begin{array}{c}7 \text { dias } \\
(\%)\end{array}$ & $\begin{array}{c}14 \text { dias } \\
(\%)\end{array}$ & $\begin{array}{c}\mathrm{N}^{\mathrm{o}} \\
\text { sementes }\end{array}$ & $\begin{array}{c}7 \text { dias } \\
(\%)\end{array}$ & $\begin{array}{c}14 \text { dias } \\
(\%)\end{array}$ & $\begin{array}{c}\mathrm{N}^{\mathrm{o}} \\
\text { sementes }\end{array}$ & $\begin{array}{c}7 \text { dias } \\
(\%)\end{array}$ & $\begin{array}{c}14 \text { dias } \\
(\%)\end{array}$ \\
\hline 2011 & 0 & 0 & 0 & 5 & 39,3 & 39,3 & 38 & 82,9 & 82,9 \\
2012 & 0 & 0 & 0 & 12 & 45,1 & 45,1 & 45 & 79,9 & 79,9 \\
2014 & 0 & 0 & 0 & 20 & 11,1 & 11,1 & 42 & 55,6 & 55,6 \\
2015 & 0 & 0 & 0 & 13 & 60,8 & 60,8 & 44 & 85,9 & 87,6 \\
\hline
\end{tabular}

\section{CONCLUSÕES}

As respostas encontradas durante o trabalho sugerem que os sais influenciam diretamente na germinação de Physalis peruviana, sendo que há uma redução no número de sementes germinadas a medida que aumenta a concentração salina devido aos efeitos osmóticos provocados pelos sais. O potencial germinativo das sementes foi reduzido, mas mesmo assim foi possível notar que ocorreu germinação mesmo na presença de elevadas concentrações salinas, sendo que a espécie mostrou-se moderadamente tolerante a esta situação abiótica.

\section{REFERÊNCIAS}

CARVALHO, N.M.; NAKAGAWA, J. Sementes: ciência, tecnologia e produção. 5.ed. Jaboticabal: FUNEP, 2012. 590p.

ESTEVES, B. S.; SUZUKI, M. S. Efeito da salinidade sobre as plantas. Oecol. Bras., V. 12, n.4, p. 662-679, 2008. 
FERREIRA D.F. Sisvar: a computer statistical analysis system. CienciaAgrotecnologia,v.35,n.6 1039-1042. 2011.

MARCOS FILHO, J. Fisiologia de sementes de plantas cultivadas. Piracicaba: Fealq, 2005. 495p.

SOUZA, C. L. M.; SOUZA, M. O.; OLIVEIRA, L. M.; PELACANI, C. R. Effect of priming on germinability and salt tolerance in seeds and seedlings of Physalis peruviana L. African Journal of Biotechnology, v. 13, n. 19, p. 1955-1960, 2014.

YILDIRIM, ERTAN; KARLIDAG, Huseyin; DURSUN, ATILLA. Salt tolerance of Physalis during germination and seedling growth. Pakistan Journal of Botany, v. 43, n. 6, p. 26732676, 2011. 